\title{
MENINGKATKAN KUALITAS PELAYANAN ORGANISASI DENGAN PERILAKU EXTRA ROLE
}

\author{
Fransisca Iriani R. Dewi ${ }^{1}$, Kiky Dwi Hapsari Saraswati \\ ${ }^{1}$ Fakultas Psikologi, Universitas Tarumanagara Jakarta \\ Email: fransiscar@fpsi.untar.ac.id \\ ${ }^{2}$ Fakultas Psikologi, Universitas Tarumanagara Jakarta \\ Email: kikys@fpsi.untar.ac.id
}

\begin{abstract}
ABSTRAK
Kinerja suatu organisasi sangat dipengaruhi oleh kinerja para anggotanya. Kinerja yang maksimal dapat dicapai bila setiap anggota melaksanakan tugas dan tanggung jawabnya dengan baik. Seiring dengan perkembangan zaman, tugas dan tanggung jawab yang perlu dipenuhi pelaksanaannya bukan hanya berkisar pada tugas dan tanggung jawab pokok, namun juga yang bersifat informal dan tidak tercantum dalam deskripsi pekerjaannya, yang disebut sebagai perilaku extra role. Dalam banyak penelitian sebelumnya, telah dibuktikan bahwa perilaku extra role berperan signifikan dalam pencapaian kinerja, baik secara individual maupun organisasional. Istilah perilaku extra role lalu dikembangkan menjadi perilaku kewargaan organisasional (PKO) dengan lima dimensi, yaitu altruism, conscientiousness, sportsmanship, civic virtue, dan courtesy. Berdasarkan konsep ini, Penulis menyelenggarakan sebuah workshop sebagai salah satu bentuk pengabdian kepada masyarakat, dengan tujuan untuk meningkatkan kualitas pelayanan organisasi. Sasaran workshop adalah pengurus dan anggota organisasi Wanita Katolik Republik Indonesia Cabang St. Laurensius, Tangerang. Workshop ini dilaksanakan pada hari Sabtu, 7 April 2018 dan dihadiri oleh 35 orang pengurus dan anggota organisasi. Berdasarkan hasil evaluasi, terdapat peningkatan pengetahuan mengenai konsep organisasi dan perilaku extra role antara sebelum dan setelah diadakannya workshop. Selain itu, secara umum, peserta merasa materi workshop ini menarik, mudah dipahami, bermanfaat dalam kehidupan sehari-hari, serta memerlukan materi sejenis untuk pengembangan diri mereka.
\end{abstract}

Kata kunci: Perilaku Extra Role, Organisasi, Kualitas Pelayanan

\section{I.PENDAHULUAN}

Dalam masyarakat terdapat berbagai organisasi kemasyarakatan yang menjadi sarana atau wadah dalam kehidupan sosial. Salah satu yang memiliki peran penting dalam kehidupan sosial adalah organisasi wanita. Tidak terkecuali situasi kondisi pada organisasi sosial kemasyarakatan bagi wanita yang berbasiskan agama Katolik. Misi yang dilaksanakan adalah: (a) memberdayakan seluruh jajaran Wanita Katolik RI mulai dari Unit yang terkecil, (b) meningkatkan kualitas hidupnya nilai-nilai Injil dan Ajaran Sosial Gereja di dalam Wanita Katolik RI, (c) meningkatkan kualitas kehidupan berdasarkan keadilan sosial, dan (d) memperjuangkan kesetaraan dan keadilan gender dalam semua aspek kehidupan. Hal penting lain yang menjadi ciri khas organisasi ini aktif di dunia ke-ormasan untuk dapat menjadi garam dan terang di masyarakat, bangsa dan negara.

Secara teoretik, keuntungan yang diperoleh seseorang ketika menjadi anggota organisasi atau kelompok sosial adalah: (1) self- knowledge dari suatu keanggotaan pada kelompok atau 
organsasi, (2) self-enhancement, serta (3) sebagai agent of change, banyak hal yang dilakukan untuk melakukan perubahan ketika bergabung dalam kelompok (Baron \& Branscombe, 2014).

Berbagai kegiatan sosial kemasyarakatan khususnya pada butir (c) yaitu: Meningkatkan kualitas kehidupan berdasarkan keadilan sosial, dan (d) Memperjuangkan kesetaraan dan keadilan gender dalam semua aspek kehidupan telah dilakukan, namun belum dilakukan secara maksimal. Berbagai kegiatan yang telah dilakukan baik untuk internal, yaitu anggota organisasi adalah: Internal: pengetahuan dan ketrampilan terkait dengan peran wanita yaitu ketrampilan merangkai bunga, menjahit, merias wajah, membantu atau menjadi tenaga relawan di klinik kesehatan di gereja, bertangung jawab atas kantin di gereja. Eksternal: kegiatan eksternal (di luar organisasi) bekerjasama dengan posyandu di lingkungan masyarakatnya secara rutin setiap bulan, memberikan bantuan makanan bagi pekerja di lingkungan masyarakat sekitar secara rutin setiap bulan.

Bagi setiap orang yang menjadi bagian dalam organisasi sosial kemasyarakatan, salah satu sikap yang harus dimiliki adalah "kesetiaan" untuk mematuhi aturan main yang telah disepakati bersama, misalnya dalam bentuk Anggaran Dasar, Anggaran Rumah Tangga, Urain Tugas (Jobs Description), dan seterusnya. Berorganisasi sangat penting perananya dalam mendewasakan pola pikir dan perilaku disamping mengembangkan pergaulan (jaringan) setiap orang, menempa diri dalam menerima tanggung jawab, memimpin dan dipimpin orang lain, melatih diri terhadap aturan main (mekanisme), dan banyak manfaat lain-lain yang bisa didapatkan dari berorganisasi. Dengan perkata lain, bahwa produktivitas organisasi belum berjalan secara maksimal. Diduga terkait dengan sumber daya manusia. Sebagai sebuah organisasi sosial kemasyarakatan, keanggotaan bersifat sukarela.

Para pengurus dan anggota memiliki latar belakang pendidikan serta pekerjaan atau profesi yang bervariasi. Berbeda-beda, kepentingannya untuk menjadi anggota, antara lain: (1) peningkatan religiusitas, (2) mengisi waktu dengan kegiatan yang bermanfaat, (3) menyalurkan bakat, dan (4) bersosialisasi. Berdasarkan wawancara dengan anggota dan pengurus organisasi tersebut, dapat dirangkum bahwa tujuan utama dari keanggotaan adalah adanya kebutuhan untuk memiliki teman sambal beraktivitas yang positif, atau Need of affiliation.

Permasalahan Mitra. Berbagai faktor yang melatar belakangi keikutsertaan atau tujuan menjadi anggota organisasi membawa dampak pada keberlangusungan atau kinerja organisasi. Tujuan organsisasi belum tentu dapat dicapai sebagaimana yang diharapkan disebabkan produktivitas rendah atau kinerja organisasi kurang baik. Situasi yang terjadi dalam organisasi sosial WKRI di Tangerang ini menunjukkan beberapa permasalahan yang harus mendapatkan perhatian. Permasalahan tersebut antara lain:

(1)Produktivitas rendah atau program kerja yang telah disusun tidak dapat dilaksanakan dengan maksimal,

(2)Team work lemah, partisipasi anggota menjadi berkurang, keanggotaan kurang solid

(3)Terjadi social loafing (kemalasan sosial), artinya anggota aktif bekerja adalah orang-orang tertentu saja, terjadi saling melempar tanggung jawab.

(4)Suasana kerja kurang kondusif. 
Namun pada praktiknya, para pengurus WKRI cabang St Laurensius banyak yang belum memahami pentingnya komitmen dalam berorganisasi, walaupun sifatny sukarela. Berpijak dari hal tersebut, penulis melalukan kegiatan menawarkan program pembekalan untuk berorganisasi bagi anggota organisasi wanita yang dilaksanakan dalam bentuk memberikan ceramah, permainan, menonton film, dan role play yang berhubungan dengan materi. Program ini bertujuan untuk memberikan gambaran tentang hal-hal yang perlu diperhatikan oleh anggota organisasi dan bagaimana mengaplikasikan hal-hal tersebut agar dapat berorganisasi dengan maksimal. Materi yang diberikan untuk mencapai tujuan tersebut adalah tentang Perilaku Kewargaan Organisasional.

Perilaku Kewargaan Organisasional adalah perilaku individu yang tidak dikategorikan atau diperhitungkan dalam sistem imbal jasa/reward yang formal, dan secara keseluruhan mempromosikan fungsi organisasi yang efektif (Organ dalam Podsakoff, Whiting Podsakoff, \& Blume, 2009). Selanjutnya, Organ menyampaikan lima dimensi perilaku kewargaan organisasional sebagai berikut: (a) altruisme adalah perilaku bijaksana dari karyawan yang siap sedia membantu orang lain dalam hal penyelesaian problem organisasi, (b) conscientiousness adalah kesadaran karyawan untuk memenuhi persyaratan minimum perusahaan yang mencakup kehadiran, kesediaan mengikuti segala peraturan yang ada dan aturan terkait hari libur atau istirahat karyawan, (c) sportsmanship adalah kesediaan karyawan dalam mentoleransi kondisi yang kurang ideal di perusahaan dengan tanpa komplain, (d) civic virtue adalah perilaku bijak karyawan dimana ia mampu mengarahkan orang lain dan dirinya untuk menghindari potensi masalah sebelum benar-benar terjadi, (e) courtesy adalah perilaku dari karyawan yang mengindikasikan kepedulian akan keberlangsungan hidup organisasi.

Selain memberikan gambaran tentang Perilaku Kewargaan Organisasional, anggota organisasi juga akan dibekali dengan cara-cara untuk mengembangkan perilaku tersebut, dengan mengacu pada dimensi-dimensi Altruism, Conscientiousness, Sportsmanship, Civic Virtue, dan Courtesy. Dengan dimilikinya pengetahuan dan cara mengaplikasikan Perilaku Kewargaan Organisasional dalam kehidupan berorganisasi, diharapkan para anggota dapat memberikan perhatian dan kontribusi lebih bagi organisasinya. Lebih jauh lagi, diharapkan organisasi dapat lebih berkembang dan mampu memberikan kontribusi yang signifikan bagi lingkungan dan masyarakat sekitarnya.

\section{II.METODE PELAKSANAAN PKM}

Program pengabdian ini dilaksanakan dalam rangka pemberdayan kelompok dengan memberikan workshop/pelatihan dan ceramah mengenai Organisasi dan Perilaku Kewargaan Organisasional. Ceramah diberikan kepada 34 orang pengurus dan anggota organisasi wanita Katolik di Tangerang. Kegiatan dilaksanakan oleh 2 orang dosen Fakultas Psikologi yang dibantu oleh 2 orang mahasiswa dan bertempat di kantor pengurus organisasi wanita.

Selain ceramah, kegiatan akan dilaksanakan juga dengan memberikan kesempatan untuk role play, menonton film, dan melakukan permainan yang berhubungan dengan materi. Sebelum materi diberikan, peserta diminta untuk mengikuti pre-test untuk mengetahui sejauh mana pengetahuan peserta tentang organisasi dan Perilaku Kewargaan Organisasional. Setelah pemberian materi 
dilaksanakan, peserta pun diminta unttuk mengerjakan post- test yang bertujuan untuk mengukur efektivitas kegiatan.

\section{III.HASIL DAN PEMBAHASAN}

Kegiatan pembekalan bagi pengurus dan anggota WKRI Cabang St. Laurensius ini dibagi dalam beberapa sesi sebagai berikut:

a. Materi : Pembukaan

Acara pembekalan dimulai pukul 08.00 - 08.30 dengan dibuka oleh Ketua WKRI. Ketua WKRI juga memperkenalkan pembicara dan menyampaikan latar belakang serta tujuan dari pelaksanaan pembekalan ini.

b. Materi: Ice Breaking

Pembekalan diawali dengan mengadakan ice breaking berupa perkenalan dengan semua peserta. Tujuannya adalah agar sesi pembekalan berjalan dengan hangat dan memancing peserta agar berperan aktif sepanjang sesi.

c. Materi: Sesi 1 (Organisasi dan Perilaku Kewargaan Organisasional)

Dalam sesi ini, pembicara menyampaikan materi mengenai definisi organisasi, ciri-ciri organisasi, ciri-ciri organisasi yang unggul, peran pengurus dan anggota organisasi dalam organisasi, serta Perilaku Kewargaan Organisasional. Tujuannya adalah agar peserta memahami konsep organisasi serta peran penting anggota dalam mensukseskan tercapainya tujuan organisasi. Selain itu pembicara juga memperkenalkan konsep Perilaku Kewargaan Organisasional sebagai salah satu aspek penting yang mendukung keberhasilan suatu organisasi.

d. Materi: Sesi 2 (Aplikasi Perilaku Kewargaan Organisasional)

Materi ini diberikan dengan membagi peserta dalam beberapa kelompok. Pembicara memberikan 4 jenis kasus yang berhubungan dengan Perilaku Kewargaan Organisasional, lalu menginstruksikan kepada peserta untuk mendiskusikannya. Tujuannya adalah agar peserta memahami contoh-contoh bentuk Perilaku Kewargaan Organisasional dalam kehidupan sehari-hari dan mampu memikirkan solusinya bila menemui masalah Perilaku Kewargaan Organisasional dalam kehidupan berorganisasi.

e. Materi: Penutup

Dalam sesi ini pembicara menarik kesimpulan dari semua materi yang disampaikan pada pembekalan ini. Pembicara juga memberikan materi evaluasi berupa post test dan reaksi peserta terhadap pembekalan yang telah diberikan. Tujuannya adalah agar pembicara dapat menilai efektivitas pembekalan dan menjadikannya sebagai bahan masukan untuk pelaksanaan yang akan datang.

Pembahasan Hasil Kegiatan PKM. Secara umum pelaksanaan PKM ini berjalan dengan lancar. Acara dimulai dan selesai tepat waktu. Pembekalan ini dihadiri oleh 34 orang anggota WKRI. Kegiatan ini dievaluasi dengan 2 metode untuk mengetahui efektivitasnya. Evaluasi yang pertama adalah untuk mengetahui sejauh mana pemahaman peserta terhadap materi seminar yang disampaikan. Untuk itu, pre- test diberikan sebelum kegiatan dimulai dan post-test diberikan setelah acara selesai. Berikut adalah hasil evaluasi yang pertama: 
Tabel 1. Hasil Pre-Test dan Post-Test

\begin{tabular}{|c|c|c|c|}
\hline No. & Nama & Hasil Pre Test & Hasil Post Test \\
\hline 1 & Brinda & 20 & 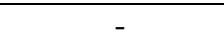 \\
\hline 2 & Vilisya & 50 & 50 \\
\hline 3 & Meiry & 50 & 70 \\
\hline 4 & Yunita & 50 & 60 \\
\hline 5 & Elly Leo & 30 & 70 \\
\hline 6 & Erleen & 30 & - \\
\hline 7 & Fonita & 70 & 90 \\
\hline 8 & Dwi & 50 & - \\
\hline 9 & Winda & 60 & - \\
\hline 10 & Friska & 50 & 80 \\
\hline 11 & Elly R. & 20 & 40 \\
\hline 12 & Kiki & 20 & 50 \\
\hline 13 & Sulistiawati & 40 & - \\
\hline 14 & Lita & 70 & 50 \\
\hline 15 & Lalan & 30 & 100 \\
\hline 16 & Yosefa & 80 & 70 \\
\hline 17 & Natalia & 60 & 100 \\
\hline 18 & Magda & 50 & 80 \\
\hline 19 & Linggar & 60 & 70 \\
\hline 20 & Agustina & 50 & 50 \\
\hline 21 & Cynthia & 50 & 90 \\
\hline 22 & Tina & 60 & - \\
\hline 23 & Theresia & 50 & 90 \\
\hline 24 & Musiati & 30 & - \\
\hline 25 & Lian Tjoe & 40 & 60 \\
\hline 26 & Corry & 10 & 50 \\
\hline 27 & Wendelina & 30 & 40 \\
\hline 28 & Liena & 30 & - \\
\hline 29 & Hefie & 40 & 80 \\
\hline 30 & Helena & 60 & 60 \\
\hline 31 & Julie & - & 60 \\
\hline 32 & Susanti & - & 50 \\
\hline 33 & Agnes & - & 90 \\
\hline 34 & Josi & - & 70 \\
\hline
\end{tabular}

Berdasarkan hasil evaluasi pertama, terdapat peningkatan rerata nilai test, yaitu rerata pretest adalah sebesar 44,67, sedangkan rerata post-test adalah sebesar 68,07. Dapat disimpulkan bahwa terdapat perbedaan pemhaman konsep perilaku extra role antara sebelum dan setelah seminar dilaksanakan. Evaluasi kedua adalah evaluasi untuk mengukur respon peserta terhadap pelaksanaan seminar. Nilai maksimal untuk penilaian dalam evaluasi ini adalah 4. Berikut adalah hasil evaluasi kedua: 
Tabel 2. Hasil Evaluasi Pelaksanaan Seminar

\begin{tabular}{clc}
\hline No. & \multicolumn{1}{c}{ Aspek yang Diukur } & Rerata Penilaian Peserta \\
\hline 1 & $\begin{array}{l}\text { Materi disampaikan dengan menarik dan mudah } \\
\text { dipahami }\end{array}$ & 3,67 \\
2 & $\begin{array}{l}\text { Materi yang disampaikan bermanfaat dalam } \\
\text { kehidupan sehari-hari }\end{array}$ & 3,87 \\
3 & Pembicara menguasai materi yang disampaikan & 3,73 \\
4 & Memerlukan materi workshop lanjutan untuk & 3,4 \\
& pengembangan diri & \\
\hline
\end{tabular}

Tabel 3. Pendapat Umum Peserta

\begin{tabular}{|c|c|}
\hline No. & Komentar Peserta \\
\hline 1 & $\begin{array}{l}\text { Sangat cocok, nih, Bu, dengan keadaan di lingkungan WK kami karena ketua } \\
\text { WK yang dulu sangat tidak berempati dengan anggotanya. Suka memaksakan } \\
\text { kehedaknya. Padahal kegiatan WK adalah kegiatan sosial yang harus dikerjakan } \\
\text { sesuai dengan hati nurani dan keikhlasan kita. }\end{array}$ \\
\hline 2 & $\begin{array}{l}\text { Diharapkan mengundang orang yang bukan anggota supaya tertarik ikut } \\
\text { berorganisasi. }\end{array}$ \\
\hline 3 & $\begin{array}{l}\text { Materi yang disampaikan bagus sekali untuk pembelajaran kita, untuk pribadi } \\
\text { dan dalam organisasi. }\end{array}$ \\
\hline 4 & Materi bagus untuk peningkatan organisasi WKRI. \\
\hline 5 & Materi sangat bagus. Sayang materi yang terakhir terkesan terburu-buru. \\
\hline 6 & $\begin{array}{l}\text { Dapat meningkatkan sikap dan perilaku yang baik dalam berorganisasi dan dapat } \\
\text { lebih baik memahami sikap-sikap untuk berorganisasi yang baik. }\end{array}$ \\
\hline 7 & Terlalu monoton, sebaiknya ada selingan seperti games, gerak, dan lagu. \\
\hline 8 & Terima kasih. Mata saya jadi terbuka. Nambah ilmu, nambah PD. \\
\hline 9 & Bagus karena simple dan mengena. \\
\hline 10 & $\begin{array}{l}\text { Seminar ini sangat bermanfaat. Selain memberikan pengetahuan, juga } \\
\text { bermanfaat untuk organisasi dan pengembangan diri sendiri. }\end{array}$ \\
\hline 11 & Materi cukup mengena. \\
\hline 12 & Materi bagus dan sangat penting untuk bekal kita berorganisasi. \\
\hline 13 & $\begin{array}{l}\text { Bagus. Boleh diadakan lagi dengan topic yang berbeda untuk mengembangkan } \\
\text { organisasi WKRI. }\end{array}$ \\
\hline 14 & Singkat, padat, jelas, dan memotivasi. \\
\hline
\end{tabular}

\section{IV.KESIMPULAN DAN SARAN}

Kesimpulan. Kesimpulan atas pelaksanaan program pembekalan ini antara lain: (1) bahwa pelaksanaan seminar ini mendapat penilaian baik oleh peserta karena rerata semua aspek di atas 3,00 . Secara lengkap digambarakan melalui pendapat dari peserta mengenai pelaksanaan seminar ini. Berikut adalah pendapat atau komentar umum yang diberikan oleh peserta. (2) mayoritas peserta menyampaikan rasa puasnya terhadap kegiatan ini dan berharap pembicara dapat memberikan materi lain. Diharapkan materi-materi tersebut dapat meningkatkan kemampuan mereka dalam berorganisasi, sehingga output organisasi pun akan lebih maksimal. Saran untuk organisasi, diharapkan keterlibatan anggota lebih banyak. Selain itu, para pengrurus dapat saling memberikan motivasi bagi anggota agar perilaku Kewargaan Organisasional dalam kehidupan berorganisasi terus diterapkan, sehingga tujuan organisasi tercapai dengan efektif. 
Ucapan Terima Kasih (Acknowledgement) penulis mengucapkan terimakasih kepada ketua WKRI cabang St Laurensius di Tangerang, serta Direktorat Penelitian dan Pengabdian kepada Masyarakat, sehingga kegiatan program pembekalan dalam rangka Pengabdian kepada Masyarakat dapat dilaksanakan.

\section{DAFTAR PUSTAKA}

Baron, B., \& Branscombe. (2014) Social psychology. Belmont. CA: Wadsworth Cengage Learning

Luthans, F (2015). Organizational Behavior - An Evidence-based Approach (13th ed). Boston: McGraw Hill Inc.

Organ, D. W. (1997). Organizational citizenship behavior: It's construct clean-up time. Human performance, 10(2), 85-97

Organ, D. W., Podsakoff, P. M., \& MacKenzie, S. B. (2006). Organizational citizenship behavior: Its nature, antecedents, and consequences. USA: Sage Publications, Inc.

Podsakoff, N. P., Whiting, S. W., Podsakoff, P. M., \& Blume, B. D. (2009). Individual- and organizational-level consequences of organizational citizenship behaviors: A meta- analysis. Journal of Applied Psychology, 94(1), 122-141 